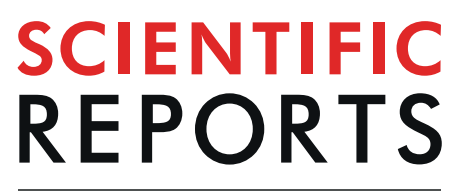

natureresearch

\title{
OPEN Magnetic nanoantioxidants with improved radical-trapping stoichiometry as stabilizers for inhibition of peroxide formation in ethereal solvents
}

\author{
Caterina Viglianisi $\mathbb{1}^{1,3^{*}}$, Alessia Scarlini ${ }^{1}$, Lorenzo Tofani ${ }^{1}$, Stefano Menichetti $\mathbb{D}^{1,3}$, \\ Andrea Baschieri ${ }^{2}$ \& Riccardo Amorati ${ }^{2,3}$
}

Graphite-coated magnetic cobalt nanoparticles (CoNPs) decorated with hindered phenolic antioxidant analogues of 2,6-di-tert-butyl-4-methylphenol (BHT, E321) provided easily removable nanoantioxidants capable of preventing the autoxidation of organic solvents as tetrahydrofuran (THF).

Tetrahydrofuran (THF) is one of the most popular ethereal solvents and together with ethyl ether, cyclopentyl methyl ether and 2-methyltetrahydrofuran, forms peroxides upon storage in the presence of $\mathrm{O}_{2}$ via an autoxidation mechanism ${ }^{1}$. Peroxides are highly unstable and represent an explosion hazard at concentrations above $100 \mathrm{ppm}^{2-5}$. Autoxidation is a radical chain reaction sustained by peroxyl radicals (ROO ${ }^{\bullet}$ which causes the oxidative degradation of organic compounds under mild conditions, leading to the formation of a variety of unwanted and in some case toxic and/or dangerous compounds including peroxides and epoxides ${ }^{1,6}$. Chain-breaking antioxidants $(\mathrm{AH})$ counteract autoxidation by quenching the chain-carrying peroxyl radicals (Eq. $1-2)^{7}$.

$$
\begin{gathered}
\mathrm{ROO} \bullet+\mathrm{AH} \rightarrow \mathrm{ROOH}+\mathrm{A} \bullet \\
\mathrm{ROO} \bullet+\mathrm{A} \bullet \rightarrow \text { non-radical products }
\end{gathered}
$$

The hindered phenol butylated hydroxytoluene (BHT, 2,6-di-tert-butyl-4-methylphenol, E 321) is the stabilizer of choice for ethereal solvents, to which it is typically added in 100-300 ppm concentrations ${ }^{8}$. However, there are some limitations in the use of BHT, for example, it is incompatible with methods requiring high optical purity due to its UV absorbance, and must be avoided with solvent purification systems (such as Pure Solv ${ }^{\mathrm{TM}}$ Micro or similar apparatuses) that permit the dispensing of small quantities of dry solvent ${ }^{9}$. In fact, BHT interacts with the filter material clogging the system, that allows only inhibitor-free solvents. Thus, to avoid dangerous peroxides formation, THF and other ethereal solvents have to be purchased frequently and in small quantities, limiting the effectiveness of these apparatuses. Indeed, an ideal solvent stabilizer should be easily and quantitatively removed just before use.

We imagined that this problem could be solved by using oxidation inhibitors linked to magnetic nanoparticles that allows their removing by decantation using a magnet (Fig. 1).

The possibility to use nanomaterials as radical trapping agents represents a relatively unexplored frontier of the development of novel nano-supported antioxidants. Their small dimensions endow unique properties, which can be used to improve the performances of antioxidants, and to obtain hybrid materials that have been named "nanoantioxidants" ${ }^{10}$. Some relevant examples include the superoxide dismutase activity of several metal and metal-oxide nanoparticles ${ }^{11,12}$, the covalent link of gallic acid to the surface of silica nanoparticles to obtain a non-migrating antioxidant ${ }^{10}$, and the combined inclusion and surface linkage of antioxidants

${ }^{1}$ Department of Chemistry "U. Schiff", University of Florence, Via della Lastruccia 3-13, 50019, Sesto Fiorentino, Firenze, Italy. 2Department of Chemistry "G. Ciamician", University of Bologna, Via S. Giacomo 11, 40126, Bologna, Italy. ${ }^{3}$ These authors contributed equally: Caterina Viglianisi, Stefano Menichetti and Riccardo Amorati. *email: caterina.viglianisi@unifi.it 


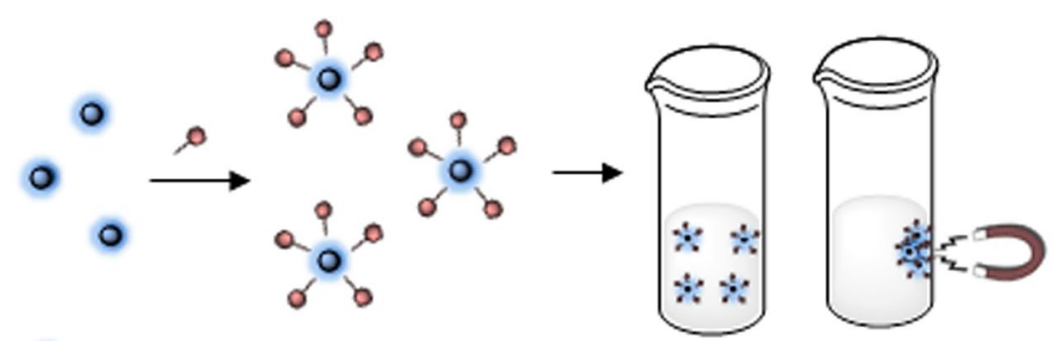

Magnetic nanoparticles CoNPs

Oxidation inhibitor

Figure 1. Schematic preparation, use and removal of nano-magnetic stabilizer systems.<smiles>C#CCCCCC#CC(C)(C)c1cc(C)cc(C(C)(C)C)c1O</smiles>

Figure 2. Synthesis of BHT-like derivatives 1 and 2 suitable for the functionalization of CoNPs-N $\mathrm{N}_{3}$ (a) 2,6-ditert-butylphenol, $\left(\mathrm{CF}_{3} \mathrm{CO}\right)_{2} \mathrm{O}$, rt, $3 \mathrm{~h}$; (b) activate $\mathrm{Zn}, \mathrm{HCl}, \mathrm{CH}_{3} \mathrm{COOH}, \mathrm{EtOH}$, reflux, $15 \mathrm{~h}$; (c) $\mathrm{SOCl}_{2}, \mathrm{MeOH}, \mathrm{rt}$, $1 \mathrm{~h}$; (d) $\mathrm{MeMgBr}, \mathrm{Et}_{2} \mathrm{O}$, rt, 16 h; (e) 2-tert-butyl-4-methylphenol, $\mathrm{CH}_{3} \mathrm{SO}_{3} \mathrm{H}, 1,2$-DCE, rt, 24 h.

to halloysite nanotubes (such as diphenylamine derivative for polymer stabilization) ${ }^{13-15}$. We have previously reported the preparation of soft ferromagnetic cobalt nanoparticles (CoNPs) decorated on the surface with Trolox (a water-soluble analogue of vitamin $\mathrm{E})^{16}$.

A problem affecting the efficiency of nanoantioxidants is that the number of radicals trapped by phenols linked to the surface of nanomaterials is usually smaller than 2 , that is the value expected from reactions 1 and 2, because of the occurrence of dimerization between the surface-bound phenoxyl radicals. Herein, we describe the synthesis of novel magnetic nanoantioxidants opportunely designed to increase the efficiency of radical trapping by the insertion of bulky groups in ortho position to the reactive $\mathrm{OH}$ group, and their use for the stabilization of tetrahydrofuran from oxidative degradation.

\section{Results and Discussion}

As magnetic nanoparticles, we choose commercially available soft ferromagnetic CoNPs of about $30 \mathrm{~nm}$ of diameter functionalized on the surface with azido groups (Turbobeads Click, CoNPs- $\mathrm{N}_{3}$ ) with a functional group-loading as $0.1 \mathrm{mmol} / \mathrm{g}^{17-19}$, that we previously reported to be suitable for the development of antioxidant systems. In fact, the metallic core is coated with roughly three graphitic layers that increases its stability and avoids pro-oxidant effects, as reported, for instance, for iron oxide magnetic nanoparticles ${ }^{20,21}$. The presence of azido groups allows the functionalization by a copper (I) catalysed azide-alkyne cycloaddition (CuAAC) 22 to obtain CoNPs-Antiox. As pendants, we chose BHT-like molecules because steric crowding around its phenoxyl group is expected to prevent the stoichiometry reduction (number of radicals trapped by each molecule) due to radical-radical coupling, and because BHT is the molecule of choice for solvents and polymers stabilization ${ }^{23-27}$.

Two different BHT-like pendants were prepared, depending on the position of the linkage respect the reactive phenolic group (compounds 1 and 2) (Fig. 2). The BHT moiety was separated from the alkyne functional group, needed for the CuAAC reaction, by a chain of nine carbon atoms. Commercially available 10-undecyn-1-ol was oxidized to 10 -undecynoic acid ${ }^{28}$ which, in a one-pot procedure, through a Friedel-Crafts acylation with 2,6-di-tert-butylphenol catalysed by trifluoroacetic anhydride followed by a Clemmensen reduction promoted by activated zinc, concentrated $\mathrm{HCl}$ and acetic acid, allowed the isolation of BHT-like derivative 1 in $44 \%$ overall yield. 


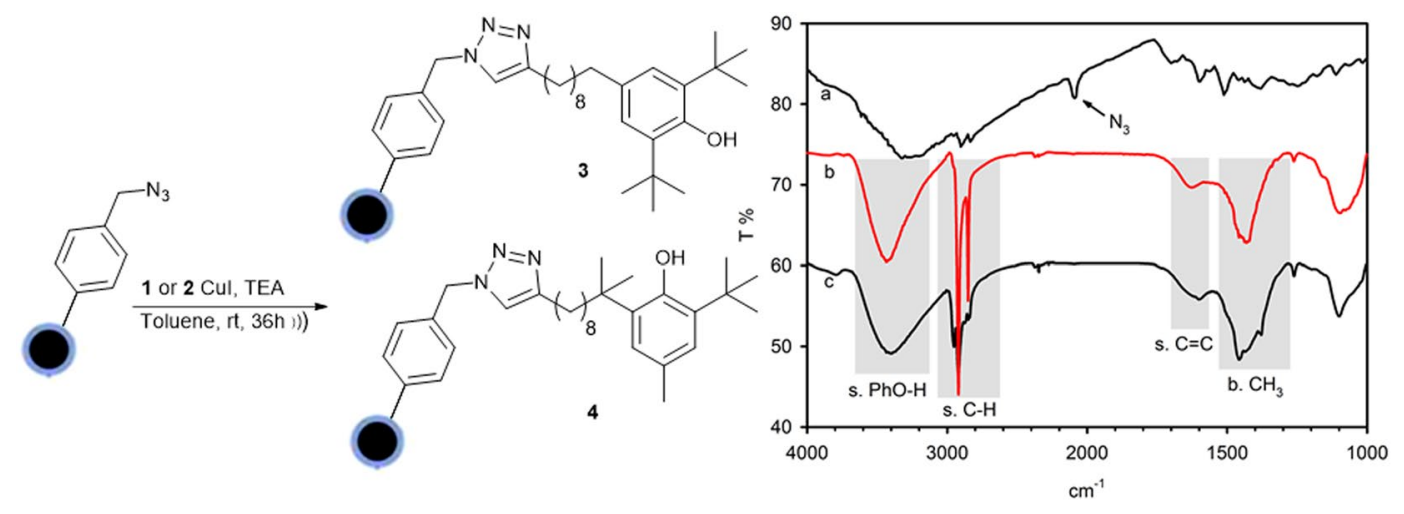

Figure 3. Functionalization of CoNPs- $\mathrm{N}_{3}$ under CuAAC conditions; Left: FT-IR (KBr pellets) spectrum of

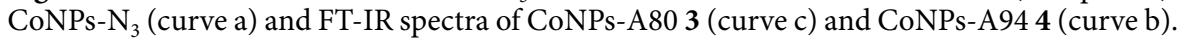

The second BHT-like alkyne derivative 2, suitable for the functionalization of CoNPs- $\mathrm{N}_{3}$, was prepared from 10-undecynoic acid, used as common starting material, that was esterified with $\mathrm{SOCl}_{2}$ and methanol ${ }^{29,30}$ and then reacted with an excess of methyl magnesium bromide to give the corresponding tertiary alcohol ${ }^{31}$. After a non-trivial optimization of the reaction conditions, the Friedel-Crafts alkylation of 2-tert-butyl-4-methylphenol with this tertiary alcohol, using $\mathrm{CH}_{3} \mathrm{SO}_{3} \mathrm{H}$ as catalyst, allowed the isolation of alkyne 2 in $27 \%$ overall yield (Fig. 2).

The derivatives 1 and 2 (10 equiv) were reacted with $\mathrm{CoNPs}_{3} \mathrm{~N}_{3}$ ( 1 equiv) using CuI ( 0.5 equiv) in the presence of triethylamine (TEA, 5 equiv) as base and anhydrous toluene as solvent (Fig. 3). The suspension was sonicated [)) )] at room temperature under nitrogen for $24 \mathrm{~h}$. After a second addition of the same amount of $\mathrm{CuI}$, the sonication was coninued for further $12 \mathrm{~h}$. The use of an excess of alkyne and a "stoichiometric" amount of the "catalytic" copper salt is mandatory since to have the complete functionalization of the surface azido groups as pointed out by FT-IR (vide infra). The nanoparticles were recovered from the reaction mixture with the aid of a neodymium-based magnet and washed with toluene $(2 \times 9 \mathrm{~mL})$. From this solution alkynes 1 and 2 , used in excess, were recovered and recycled. Trace of residual $\mathrm{Cu}(\mathrm{I})$ salt "trapped" on CoNPS surface were removed by washing with a solution of $33 \% \mathrm{NH}_{3} / \mathrm{EtOH}(2 / 1,5 \mathrm{~mL})$ under sonication for $30 \mathrm{~min}$. Then the solution was removed, and the nanoparticles washed with, in sequence, water $(2 \times 4 \mathrm{~mL})$, EtOH $(2 \times 4 \mathrm{~mL})$ and DCM $(2 \times 4 \mathrm{~mL})$. Each washing step consisted of suspending the particles in the solvent, sonication $(5 \mathrm{~min})$ and retracting the particles from the solvent by the aid of the magnet. The functionalization of CoNPs- $\mathrm{N}_{3}$ to CoNPs-A80 (3) and CoNPs-A94 (4) could be easily detected by FT-IR (KBr pellets). From the complete disappearance of the $\mathrm{N}_{3}$ stretching peak at $2090 \mathrm{~cm}^{-1}$ we considered that the yield of the functionalization was $100 \%$ and relying on manufacturer data to assess the particle loading $(0.1 \mathrm{mmol} / \mathrm{g})$ it was possible to calculate the corresponding amount of antioxidant moieties (Fig. 3$)^{32}$.

The antioxidant activity of the CoNPs-A80 (3) and CoNPs-A94 (4) was assessed by measuring the inhibition of the autoxidation of cumene (isopropylbenzene), a reference substrate for autoxidation studies, initiated by azobis(isobutyronitrile) (AIBN) at $30^{\circ} \mathrm{C}$ in benzonitrile (see Scheme $\mathrm{S} 1$ in the ESM) ${ }^{33}$. The reaction was followed by using an automatic gas absorption apparatus, based on a pressure transducer, built in our laboratory ${ }^{33}$. Figure 4 show the typical oxygen consumption traces recorded during the autoxidation of cumene in the presence of BHT and of the CoNPs-Antiox $\mathbf{3}$ and $\mathbf{4}$ in benzonitrile. CoNPs-Antiox generated an inhibition period, which was similar to that caused by BHT when used at a concentration corresponding to the molarity of the active phenolic moiety present on the nanoparticles, considering the quantitative functionalization of all the pending azide groups (see Fig. 4). By using a well assessed kinetic treatment (see ESM) ${ }^{33}$, from the $\mathrm{O}_{2}$ consumption traces the rate constants for the reaction with peroxyl radicals were determined as $(7.0 \pm 0.6) \times 10^{3}$ $\mathrm{M}^{-1} \mathrm{~s}^{-1}$ for BHT, in good agreement with the literature value considering the kinetic solvent effect ${ }^{34,35}$, and $(4.0 \pm 0.5) \times 10^{3}$ or $(2.6 \pm 0.5) \times 10^{3} \mathrm{M}^{-1} \mathrm{~s}^{-1}$ for the BHT moieties present on CoNPs-A80 3 and CoNPs-A94 4, respectively.

The slightly lower $\mathrm{k}_{\text {inh }}$ value of CoNPs-Antiox $\mathbf{3}$ and $\mathbf{4}$ is likely due to steric shielding experienced on the surface of the nanoparticle. The stoichiometry of radical trapping (n) was determined as $2.2 \pm 0.2$ for BHT and $2.3 \pm 0.2$ or $\geq 4.2$ for each BHT moiety present on CoNPs-A94 4 and CoNPs-A80 3, respectively. The unexpected large $n$ value of 3 may derive from the occurrence of secondary radical trapping mechanisms involving the formation of quinone methides and regeneration of the phenolic moiety by solvent addition ${ }^{36}$. These results can be compared to those obtained with unhindered phenols (such as Trolox ${ }^{14,16}$ or curcumin ${ }^{15}$ ) covalently linked to the surfaces of nanomaterials, as they were found to trap about one $\mathrm{ROO}^{\bullet}$ radical per molecule of antioxidant. This remarkable difference enlightens the role of the bulky tert butyl groups in stabilizing the phenoxyl radicals and ensuring a good antioxidant effect to surface-bound phenols.

The efficacy of 3 (CoNps-A80) and 4 (CoNPs-A94) as stabilizers for ethereal solvents was evaluated by monitoring the development of hydroperoxides in THF by using a commercially available colorimetric assay (see Section 1 in the ESM).

In the presence of hydroperoxides in concentration higher than $1 \mathrm{mg} / \mathrm{L}$, the colour of the test strip turns from white to blue and a quantification can be done by comparison to a colour scale (Fig. 5 inset C). The determination 


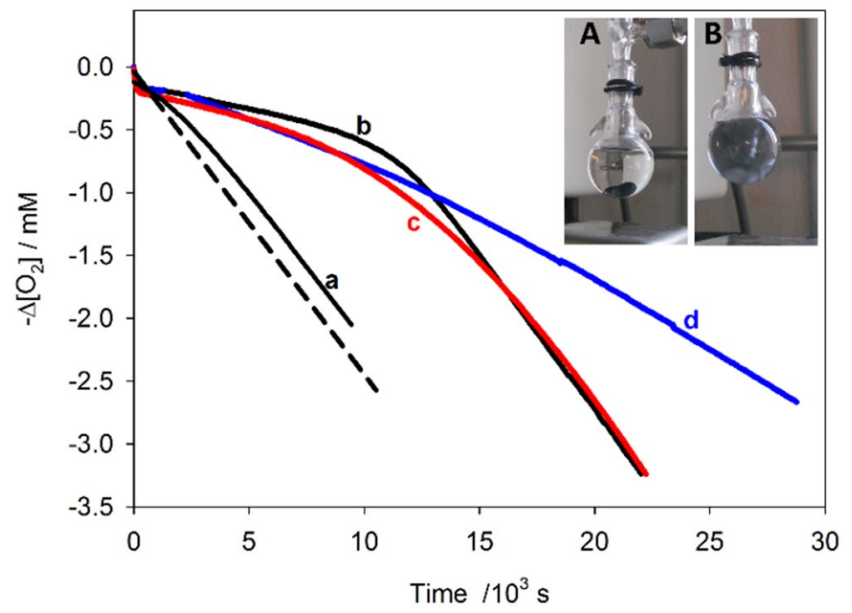

Figure 4. Oxygen consumption measured during the autoxidation of cumene $(4.3 \mathrm{M})$ initiated by AIBN $\left(25 \mathrm{mM}\right.$, rate of initiation $\left(R_{i}\right)(2.2 \pm 0.1) \times 10^{-9} \mathrm{M}^{-1} \mathrm{~s}^{-1}$ at $30^{\circ} \mathrm{C}$ in benzonitrile without antioxidants (dashed line) or in the presence of (a) CoNPs- $\mathrm{N}_{3}(0.18 \mathrm{mg} / \mathrm{mL})$; (b) BHT $(18 \mu \mathrm{M})$, (c) CoNPs-A94 4 and (d) CoNPs-A80 3 (both $0.18 \mathrm{mg} / \mathrm{mL}$, corresponding to $18 \mu \mathrm{M}$ of linked BHT units). Magnetic nanoparticles adhered to the stir bar (inset A) but were homogeneously dispersed in solution when stirring was switched on (inset B).
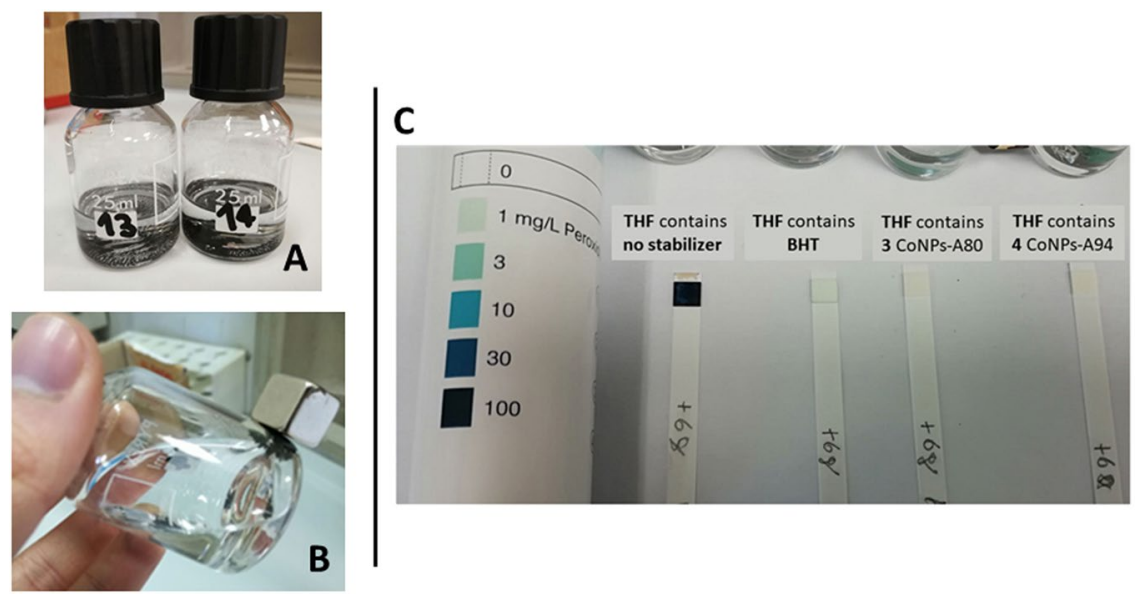

Figure 5. CoNPs-Antiox 3 and $\mathbf{4}$ suspended in THF (inset A) and recovered with a neodymium magnet (inset B), peroxide test strips (QUANTOFIX Peroxide 100, inset C).

of peroxides formation in THF was done in a series of THF samples containing BHT, CoNPs-Antiox $\mathbf{3}$ and $\mathbf{4}$ all at $250 \mathrm{ppm}$ (referred to the phenolic moieties) stored in clear glass vials at ambient light under continuous stirring. These conditions have been chosen to accelerate the oxidation and reduce the times of investigation. Actually, we proved that without continuous mixing the rate of peroxides formation increases sensibly. As shown in Fig. 5 inset $\mathrm{C}$, after six day the THF sample without stabilizer reached a concentration of peroxides bigger than $100 \mathrm{mg} / \mathrm{L}$ as evident from the stick turning dark blue, the samples with BHT is about $1 \mathrm{mg} / \mathrm{L}$, while those with CoNPs-A80 3 and CoNPs-A94 4, inhibited the formation of peroxides, experimental details and pictures of test strips at different times are available in the ESM, see Fig. S3). The semi-quantitative strips peroxides tester does not allow to point out difference between the two nanoantioxidants materials 3 and $\mathbf{4}$. However in Fig. 4 is shown the ability of both 3 and 4 in inhibiting peroxide formation measured in comparation with BHT. The quantitative removal of the nanomagnetic stabilizers could be easily accomplished by decantation using a neodymium magnet (Fig. 5 insets $\mathrm{A}$ and $\mathrm{B}$ ). The weight of recovered CoNPs, after carefully drying with a $\mathrm{N}_{2}$ stream, was identical to that added $\pm 5 \%$.

In conclusion, magnetic nanoparticles CoNPs-Antiox $\mathbf{3}$ and $\mathbf{4}$ behave as good antioxidants able to inhibit the oxidative degradation of THF, an ethereal solvent of widespread use, with the possibility to simply remove the inhibitor with the aid of a magnet. The presence of bulky substituents ortho to the reactive $\mathrm{OH}$ group allowed to obtain a radical trapping stoichiometry superior to that of other phenols bound to nanomaterials. This approach avoids time and energy consuming procedures to remove stabilizers from easily oxidizable solvents or the use of potentially dangerous inhibitors-free solvents. Although, costs of CoNPs stabilizers reported are much higher than BHT, the problems related with the use of ethereal solvents without stabilizers in automatic drying 
dispensers may indicate a niche market for these materials. Indeed, we have preliminary similar result on the inhibition of peroxide formation in diethyl ether. Future work will aim to explore the possibility to improve the dispersion in organic solvents of different polarity and to obtain nanomagntic stabilizers able to prevent non-oxidative decompositions.

\section{Methods}

General information. $\quad{ }^{1} \mathrm{H}$ - and ${ }^{13} \mathrm{C}-\mathrm{NMR}$ spectra were recorded with Varian Gemini 200 or Varian Mercury Plus 400. FT-IR spectra were recorded with FT Infrared Spectrometer 1600 Perkin-Elmer in $\mathrm{CDCl}_{3}$ solutions or KBr. GC-MS spectra were recorded with a QMD 100 Carlo Erba. ESI-MS spectra were recorded with a JEOL MStation JMS700. Melting points were measured with Stuart SMP50 Automatic Melting point. All the reactions were monitored by TLC on commercially available precoated plates (silica gel $60 \mathrm{~F} 254$ ) and the products were visualized with acidic vanillin solution. Silica gel 60 (230-400 mesh) was used for column chromatography. Commercially available reagents and catalysts were used as obtained from freshly open container without further purifications. Dry solvents were obtained by Pure Solv ${ }^{\mathrm{TM}}$ Micro Solvent Purification Systems. $\mathrm{CHCl}_{3}$ was washed 10 times with deionized water, dried on anhydrous $\mathrm{CaCl}_{2} . \mathrm{Et}_{3} \mathrm{~N}$ was distilled over $\mathrm{KOH}$. Cobalt nanoparticles were purchased from Turbobeads Llc; TurboBeads Click (CoNPs- $\left.\mathrm{N}_{3}\right)$ are carbon coated ferromagnetic cobalt nanoparticles (diameter $30 \mathrm{~nm}$ ) which have a covalent azide functionality $(0.1 \mathrm{mmol} / \mathrm{g})$. Reactions with CoNPs were carried out under sonication with an ultrasonic bath (Sonorex RK 255 H-R, Bandelin). All air and moisture sensitive reactions were carried out in oven-dried glassware under a nitrogen atmosphere using cannulas and septa. Solvents were dried following standard procedures. Commercial zinc dust $(\varnothing<10 \mu \mathrm{m})$ was activated by stirring for $4 \mathrm{~min}$ with $2 \% \mathrm{HCl}$. The zinc was immediately filtered in vacuo, washed to neutrality with water, and then washed with ethanol, acetone, and $\mathrm{Et}_{2} \mathrm{O}$. The resulting power was dried at $90^{\circ} \mathrm{C}$ under vacuum for $10 \mathrm{~min}$ and immediately used.

Synthesis of new compounds. Undec-10-ynoic acid. To a solution $0.05 \mathrm{M}$ of 10 -undecyn-1-ol (971 mg, $5.77 \mathrm{mmol})$ in acetone $(160 \mathrm{~mL}), \mathrm{Na}_{2} \mathrm{Cr}_{2} \mathrm{O}_{7} \times 2 \mathrm{H}_{2} \mathrm{O}(4304 \mathrm{mg}, 14.44 \mathrm{mmol})$ and deionized water $(5 \mathrm{~mL})$ were added at $0^{\circ} \mathrm{C}$. Then conc. $\mathrm{H}_{2} \mathrm{SO}_{4}(1.5 \mathrm{~mL})$ was added dropwise at $0^{\circ} \mathrm{C}$ and the reaction mixture was left under magnetic stirring for $15 \mathrm{~min}$. and filtered. The filtrate was extracted with AcOEt $(3 \times 30 \mathrm{~mL})$ and the organic phase washed with water $(3 \times 30 \mathrm{~mL})$ and brine $(40 \mathrm{~mL})$, dried over $\mathrm{Na}_{2} \mathrm{SO}_{4}$ and concentrated in vacuo. The desired product was obtained as a white solid without any further purification $(1000 \mathrm{mg}, 94 \%$ yield $) .{ }^{1} \mathrm{H}-\mathrm{NMR}\left(\mathrm{CDCl}_{3}, 200 \mathrm{MHz}\right) \delta$ $1.26-1.67(\mathrm{~m}, 12 \mathrm{H}), 1.94(\mathrm{t}, J=2.6 \mathrm{~Hz}, 1 \mathrm{H}), 2.18(\mathrm{dt}, J=6.9 \mathrm{~Hz}, J=2.6 \mathrm{~Hz}, 2 \mathrm{H}), 2.35(\mathrm{t}, J=7.4 \mathrm{~Hz}, 2 \mathrm{H})$. 2,6-Di-tert-butyl-4-undec-10-ynyl-phenol (1). Undec-10-ynoic acid (484 mg, $2.66 \mathrm{mmol}$ ) was dissolved in $440 \mu \mathrm{L}$ of trifluoroacetic anhydride, then after $10 \mathrm{~min} 2,6$-di-tert-butylphenol $(413 \mathrm{mg}, 2.00 \mathrm{mmol})$ was added at $0{ }^{\circ} \mathrm{C}$. The so formed brown solution was stirred at $0{ }^{\circ} \mathrm{C}$ for $30 \mathrm{~min}$. and then at room temperature until the disappearance of the starting phenol after $3 \mathrm{~h}$ (eluent for TLC control: $\mathrm{Ep} / \mathrm{Et}_{2} \mathrm{O}$ 10/1). To the resulting dark solution absolute EtOH $(10 \mathrm{~mL})$, glacial acetic acid $(5 \mathrm{~mL})$ and $37 \% \mathrm{HCl}(3.0 \mathrm{~mL})$ were added, then the mixture was heated to reflux and activated $\mathrm{Zn}$ dust $(<10 \mu \mathrm{m}, 3000 \mathrm{mg}, 46 \mathrm{mmol})$ was added in small portions. The resulting colourless suspension was vigorously stirred under reflux for $18 \mathrm{~h}$, then after TLC control (eluent: $\mathrm{Ep} / \mathrm{Et}_{2} \mathrm{O}$ 15/1) the absence of the intermediate ketone was demonstrated, and the reaction was quenched with saturated aq. $\mathrm{NaHCO}_{3}$. The residual zinc was filtered off and the filtrate was extracted with petroleum ether $(3 \times 15 \mathrm{~mL})$, then the organic phase was washed with saturated aq. $\mathrm{NaHCO}_{3}(3 \times 20 \mathrm{~mL})$ and water $(3 \times 20 \mathrm{~mL})$. The organic phase was dried over anhydrous $\mathrm{Na}_{2} \mathrm{SO}_{4}$ and evaporated in vacuum furnishing a yellow oil that was purified by silica gel column chromatography (petroleum ether/DCM 10/1), giving desired product as a colourless oil of (306 mg, 44\% yield). ${ }^{1} \mathrm{H}-\mathrm{NMR}\left(\mathrm{CDCl}_{3}, 400 \mathrm{MHz}\right) \delta 1.31-1.60(\mathrm{~m}, 32 \mathrm{H}), 1.95(\mathrm{t}, J=2.6 \mathrm{~Hz}, 1 \mathrm{H}), 2.19(\mathrm{dt}, J=7.2 \mathrm{~Hz}, J=2.6 \mathrm{~Hz}$ $2 \mathrm{H}), 2.51(\mathrm{t}, J=8.0 \mathrm{~Hz}, 2 \mathrm{H}), 5.04(\mathrm{~s}, 1 \mathrm{H}), 6.98(\mathrm{~s}, 2 \mathrm{H}) .{ }^{13} \mathrm{C}-\mathrm{NMR}\left(\mathrm{CDCl}_{3}, 100 \mathrm{MHz}\right) \delta 18.4,28.5,28.7,29.1,29.5$, 29.6, 30.3, 32.0, 34.2, 36.0, 68.0, 84.8, 124.8, 133.47, 135.50, 151.6. IR $\left(\mathrm{CDCl}_{3}, \mathrm{~cm}^{-1}\right) \nu 3643,3308,2931,2857$, $2116,1458,1435$. MS (ESI) m/z $355.58[\mathrm{M}-\mathrm{H}]^{-}$. Undec-10-ynoic acid methyl ester. Thionyl chloride $(600 \mu \mathrm{L}$, $8.24 \mathrm{mmol}$ ) was added at $-15^{\circ} \mathrm{C}$ to a solution of undec- 10 -ynoic acid $(750 \mathrm{mg}, 4.12 \mathrm{mmol})$ in anhydrous $\mathrm{MeOH}$ $(21 \mathrm{~mL})$. The reaction mixture was left under magnetic stirring at room temperature for $1 \mathrm{~h}$, then the solvent was evaporated. After the dilution with water, the mixture was extracted with $\mathrm{Et}_{2} \mathrm{O}(4 \times 20 \mathrm{~mL})$, washed with water until $\mathrm{pH}=7$ and finally with brine. The organic phase was dried over $\mathrm{Na}_{2} \mathrm{SO}_{4}$ and concentrated in vacuo, affording the desired ester as a yellow oil without any further purification $(701 \mathrm{mg}, 87 \%) .{ }^{1} \mathrm{H}-\mathrm{NMR}\left(\mathrm{CDCl}_{3}, 200 \mathrm{MHz}\right)$ $\delta 1.31-1.67(\mathrm{~m}, 12 \mathrm{H}), 1.93(\mathrm{t}, J=2.6 \mathrm{~Hz}, 1 \mathrm{H}), 2.18(\mathrm{dt}, J=6.9 \mathrm{~Hz}, J=2.6 \mathrm{~Hz}, 2 \mathrm{H}), 2.30(\mathrm{t}, J=7.4 \mathrm{~Hz}, 2 \mathrm{H}), 3.66(\mathrm{~s}$, $3 \mathrm{H})$. 2-Methyl-dodec-11-yn-2-ol. In a Schlenk tube, to a solution of undec-10-ynoic acid methyl ester (1009 mg,

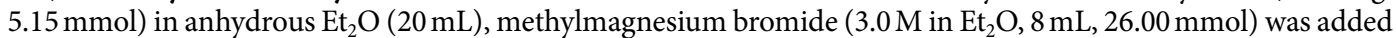
dropwise at $-78^{\circ} \mathrm{C}$. The mixture was left under magnetic stirring and $\mathrm{N}_{2}$ atmosphere allowing warming to room temperature, then after $15 \mathrm{~h}$ it was quenched with ice and acidified to $\mathrm{pH} 4$ with aq. $\mathrm{HCl} 3 \mathrm{~N}$. The so-obtained suspension was extracted with AcOEt $(3 \times 20 \mathrm{~mL})$, then collected organic phases were washed with water $(3 \times 10 \mathrm{~mL})$, dried over anhydrous $\mathrm{Na}_{2} \mathrm{SO}_{4}$ and evaporated in vacuum, furnishing a crude that was purified through flash column chromatography (petroleum ether/AcOEt 5/1) affording the desired product as a colourless oil (973 mg, 96\%). ${ }^{1} \mathrm{H}-\mathrm{NMR}\left(\mathrm{CDCl}_{3}, 400 \mathrm{MHz}\right) \delta 1.20(\mathrm{~s}, 6 \mathrm{H}), 1.29-1.53(\mathrm{~m}, 14 \mathrm{H}), 1.93(\mathrm{t}, \mathrm{J}=2.6 \mathrm{~Hz}, 1 \mathrm{H}), 2.17$ $(\mathrm{dt}, J=7.2 \mathrm{~Hz}, J=2.6 \mathrm{~Hz}, 2 \mathrm{H}) .{ }^{13} \mathrm{C}-\mathrm{NMR}\left(\mathrm{CDCl}_{3}, 100 \mathrm{MHz}\right) \delta 18.4,24.3,28.4,28.7,29.0,29.2,29.5,30.1,44.0$, 68.1, 71.0, 84.8. IR $\left(\mathrm{CDCl}_{3}, \mathrm{~cm}^{-1}\right) \nu 3607,3308,2934,2858,2116,1467$. 2-tert-Butyl-6-(1,1-dimethyl-undec10-ynyl)-4-methylphenol (2). A solution of 2-methyl-dodec-11-yn-2-ol (200 mg, $1.02 \mathrm{mmol})$ and 2-tert-butyl-4-methylphenol (170 mg, $1.04 \mathrm{mmol})$ in 1,2-DCE $(6 \mathrm{~mL})$ was added dropwise at $0{ }^{\circ} \mathrm{C}$ to a suspension of $\mathrm{CH}_{3} \mathrm{SO}_{3} \mathrm{H}$ ( $\left.439 \mathrm{mg}, 4.57 \mathrm{mmol}\right)$ in 1,2-DCE ( $1 \mathrm{~mL}$ ). The resulting red solution was left under magnetic stirring at room temperature, monitored by TLC (eluent: petroleum ether/ $\mathrm{Et}_{2} \mathrm{O} 4 / 1$ and petroleum ether). After $24 \mathrm{~h}$ the reaction was quenched with saturated aq. $\mathrm{NaHCO}_{3}$, then the resulting mixture was diluted with DCM $(30 \mathrm{~mL})$ and washed with saturated aq. $\mathrm{NaHCO}_{3}(3 \times 10 \mathrm{~mL})$ and water $(3 \times 10 \mathrm{~mL})$. The organic phase was dried over 
anhydrous $\mathrm{Na}_{2} \mathrm{SO}_{4}$ and evaporated in vacuo furnishing a yellow oil that was purified by silica gel column chromatography (petroleum ether fallowed by petroleum ether/DCM 10/1), giving the desired product 2 as a yellow oil (94 mg, 27\% yield). ${ }^{1} \mathrm{H}-\mathrm{NMR}\left(\mathrm{CDCl}_{3}, 400 \mathrm{MHz}\right) \delta 1.04-1.39(\mathrm{~m}, 10 \mathrm{H}), 1.40(\mathrm{~s}, 6 \mathrm{H}), 1.43(\mathrm{~s}, 9 \mathrm{H}), 1.46-1.54(\mathrm{~m}$, $2 \mathrm{H}), 1.77-1.81(\mathrm{~m}, 2 \mathrm{H}), 1.94(\mathrm{t}, J=2.6 \mathrm{~Hz}, 1 \mathrm{H}), 2.17(\mathrm{dt}, J=7.0 \mathrm{~Hz}, J=2.6 \mathrm{~Hz}, 2 \mathrm{H}), 2.28(\mathrm{~s}, 3 \mathrm{H}), 5.02(\mathrm{~s}, 1 \mathrm{H})$, $6.91(\mathrm{~s}, 1 \mathrm{H}), 6.99(\mathrm{~s}, 1 \mathrm{H}) .{ }^{13} \mathrm{C}-\mathrm{NMR}\left(\mathrm{CDCl}_{3}, 100 \mathrm{MHz}\right) \delta 18.40,18.43,21.3,25.1,28.5$ 28.7, 29.0, 29.19, 29.24, 30.2, 30.3, 34.2 37.7, 41.8, 68.1, 84.8, 125.5, 126.6, 128.0, 134.1, 135.5, 151.5. IR $\left(\mathrm{CDCl}_{3}, \mathrm{~cm}^{-1}\right) \nu 3632,3308,2931$,

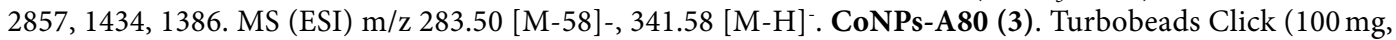
$0.1 \mathrm{mmol} / \mathrm{g}$ azide-loading, $0.01 \mathrm{mmol})$ were washed with degassed toluene $(3 \times 1 \mathrm{~mL})$ and suspended in the same solvent $(4 \mathrm{~mL})$ by sonication $(10 \mathrm{~min})$ before $1(33 \mathrm{mg}, 0.1 \mathrm{mmol}$,) TEA $(7 \mu \mathrm{L}, 0.05 \mathrm{mmol})$ and CuI ( $1 \mathrm{mg}$, $0.005 \mathrm{mmol}$ ) were added. The resulting slurry was sonicated for $24 \mathrm{~h}$ at room temperature under a nitrogen atmosphere, then a second crop of $\mathrm{CuI}(1 \mathrm{mg}, 0.005 \mathrm{mmol})$ was added and the mixture sonicated for additional $12 \mathrm{~h}$. The nanoparticles were recovered from the reaction mixture with the aid of a neodymium-based magnet and washed with toluene $(2 \times 9 \mathrm{~mL})$. Adventitious trace of residual $\mathrm{Cu}(\mathrm{I})$ salts were removed by washing with a solution of $33 \%$ ammonia/EtOH $(2 / 1,5 \mathrm{~mL})$ under sonication for $30 \mathrm{~min}$, then the solution was removed and the nanoparticles washed twice with, in sequence, water $(2 \times 4 \mathrm{~mL})$, EtOH $(2 \times 4 \mathrm{~mL})$ and DCM $(2 \times 4 \mathrm{~mL})$ sequentially. Each washing step consisted of suspending the particles in the solvent, sonication $(5 \mathrm{~min})$ and retracting the particles from the solvent by the aid of the magnet. After the last washing step, the particles were dried in vacuum overnight and recovered as a black solid of $111 \mathrm{mg}$. IR $\left(\mathrm{KBr}, \mathrm{cm}^{-1}\right) \nu 3435,2919,2851,1620,1430,1261,1095$. CoNPs-A94 (4). Turbobeads Click (100 mg, $0.1 \mathrm{mmol} / \mathrm{g}$ azide-loading, $0.01 \mathrm{mmol}$ ) were washed with degassed toluene $(3 \times 1 \mathrm{~mL})$ and suspended in the same solvent $(4 \mathrm{~mL})$ by sonication $(10 \mathrm{~min})$ before $2(34 \mathrm{mg}, 0.1 \mathrm{mmol}$,) TEA $(7 \mu \mathrm{L}, 0.05 \mathrm{mmol})$ and $\mathrm{CuI}(1 \mathrm{mg}, 0.005 \mathrm{mmol})$ were added. The resulting slurry was sonicated for $24 \mathrm{~h}$ at room temperature under a nitrogen atmosphere, then a second crop of $\mathrm{CuI}(1 \mathrm{mg}, 0.005 \mathrm{mmol})$ was added and the mixture sonicated for additional $12 \mathrm{~h}$. The nanoparticles were recovered from the reaction mixture with the aid of a neodymium-based magnet and washed with toluene $(2 \times 9 \mathrm{~mL})$. Adventitious trace of residual $\mathrm{Cu}(\mathrm{I})$ salts were removed by washing with a solution of $33 \%$ ammonia/EtOH $(2 / 1,5 \mathrm{~mL})$ under sonication for $30 \mathrm{~min}$, then the solution was removed and the nanoparticles washed twice with, in sequence, water $(2 \times 4 \mathrm{~mL})$, EtOH $(2 \times 4 \mathrm{~mL})$ and DCM $(2 \times 4 \mathrm{~mL})$ sequentially. Each washing step consisted of suspending the particles in the solvent, sonication $(5 \mathrm{~min})$ and retracting the particles from the solvent by the aid of the magnet. After the last washing step, the particles were dried in vacuum overnight and recovered as a black solid of $98 \mathrm{mg}$. IR $\left(\mathrm{KBr}, \mathrm{cm}^{-1}\right) \nu 3400,2952$, 2919, 1601, 1457, 1261, 1099.

\section{Data availability}

Electronic Supplementary Material: Further details of autoxidation experiments, semi-quantitative determination of the peroxides, NMR spectra are available in the online version of this article at www.nature.com/articles/ s41598-019-53531-5.

Received: 31 May 2019; Accepted: 31 October 2019;

Published online: 20 November 2019

\section{References}

1. Amorati, R., Baschieri, A., Morroni, G., Gambino, R. \& Valgimigli, L. Peroxyl radical reactions in water solution: A gym for protoncoupled electron-transfer theories. Chem. Eur. J. 22, 7924-7934, https://doi.org/10.1002/chem.201504492 (2016).

2. Matsubara, S. H. S. \& Suzuki, H. An ab initio and dft study of the autoxidation of THF and THP. Org. Biomol. Chem. 13, 4686-4692, https://doi.org/10.1039/C5OB00012B (2015).

3. Di Tommaso, S. et al. A mechanistic and experimental study on the diethyl ether oxidation. Process. Saf. Prog. 33, 64-69, https://doi. org/10.1002/prs.11621 (2014)

4. Di Tommaso, S., Rotureau, P., Crescenzi, O. \& Adamo, C. Oxidation mechanism of diethyl ether: a complex process for a simple molecule. Phys. Chem. Chem. Phys. 13, 14636-14645, https://doi.org/10.1039/C1CP21357A (2011).

5. Hoshino, H., Sakakibara, K. \& Watanabe, K. Autoxidation resistant cyclopentyl methyl ether. Chem. Lett. 37, 774-775, https://doi. org/10.1246/cl.2008.774 (2008).

6. Zielinski, Z. A. M. \& Pratt, D. A. Lipid peroxidation: Kinetics, mechanisms, and products. J. Org. Chem. 82, 2817-2825, https://doi. org/10.1021/acs.joc.7b00152 (2017)

7. Menichetti, S. et al. Role of noncovalent sulfur $\cdots$ oxygen interactions in phenoxyl radical stabilization: Synthesis of super tocopherollike antioxidants. Org. Lett. 18, 5464-5467, https://doi.org/10.1021/acs.orglett.6b02557 (2016).

8. Yehye, W. A. et al. Understanding the chemistry behind the antioxidant activities of butylated hydroxytoluene (BHT): A review. Eur. J. Med. Chem. 101, 295-312, https://doi.org/10.1016/j.ejmech.2015.06.026 (2015).

9. Freemantle, P. Pure solvTM micro solvent purification systems easy access to freshly prepared anhydrous solvents. Aldrich Chemfiles 10, $24(2010)$

10. Deligiannakis, Y., Sotiriou, G. A. \& Pratsinis, S. E. Antioxidant and antiradical $\mathrm{SiO}_{2}$ nanoparticles covalently functionalized with gallic acid. ACS Appl. Mater. Interfaces 4, 6609-6617, https://doi.org/10.1021/am301751s (2012).

11. Valgimigli, L., Baschieri, A. \& Amorati, R. Antioxidant activity of nanomaterials. J. Mater. Chem. B 6, 2036-2051, https://doi. org/10.1039/C8TB00107C (2018).

12. Baschieri, A., Del Secco, B., Zaccheroni, N., Valgimigli, L. \& Amorati, R. The role of onium salts in the pro-oxidant effect of gold nanoparticles in lipophilic environments. Chem. Eur. J. 24, 9113-9119, https://doi.org/10.1002/chem.201801110 (2018).

13. Fu, Y. et al. Highly aging-resistant elastomers doped with antioxidant-loaded clay nanotubes. ACS Appl. Mater. Interfaces 7, 8156-8165, https://doi.org/10.1021/acsami.5b00993 (2015).

14. Massaro, M. et al. A synergic nanoantioxidant based on covalently modified halloysite-trolox nanotubes with intra-lumen loaded quercetin. J. Mater. Chem. B 4, 2229-2241, https://doi.org/10.1039/C6TB00126B (2016).

15. Massaro, R. et al. Direct chemical grafted curcumin on halloysite nanotubes as dual-responsive prodrug for pharmacological applications. Colloids Surf. B 140, 505-513, https://doi.org/10.1016/j.colsurfb.2016.01.025 (2016).

16. Viglianisi, C. et al. Linking an alpha-tocopherol derivative to cobalt(0) nanomagnets: Magnetically responsive antioxidants with superior radical trapping activity and reduced cytotoxicity. Chem. Eur. J. 20, 6857-6860, https://doi.org/10.1002/chem.201402289 (2014). 
17. Koehler, F. M. et al. Magnetic EDTA: coupling heavy metal chelators to metal nanomagnets for rapid removal of cadmium, lead and copper from contaminated water. Chem. Commun. 32, 4862-4864, https://doi.org/10.1039/B909447D (2009).

18. Rossier, M. et al. Gold adsorption on the carbon surface of C/Co nanoparticles allows magnetic extraction from extremely diluted aqueous solutions. J. Mater. Chem. 19, 8239-8243, https://doi.org/10.1039/B913744K (2009).

19. Herrmann, I. K. et al. Blood purification using functionalized/core shell nanomagnets. Small 6, 1388-1392, https://doi.org/10.1002/ smll.201000438 (2010).

20. Zhang, S. \& Zhao, D. Advances in magnetic materials: Processing, properties and performance, https://doi.org/10.4324/9781315371573 (2017).

21. Grass, R. N., Athanassiou, E. K. \& Stark, W. J. Covalently functionalized cobalt nanoparticles as a platform for magnetic separations in organic synthesis. Angew. Chem. Int. Ed. 46, 4909-4912, https://doi.org/10.1002/anie.200700613 (2007).

22. Himo, T. et al. Copper(I)-catalyzed synthesis of azoles. dft study predicts unprecedented reactivity and intermediates. J. Am. Chem. Soc. 127, 210-216, https://doi.org/10.1021/ja0471525 (2005).

23. Menichetti, S. et al. Ethylene-based copolymers with tunable content of polymerizable hindered phenols as nonreleasing macromolecular additives. J. Polym. Sci. A 46, 6393-6406, https://doi.org/10.1002/pola.22940 (2008).

24. Boragno, L. et al. Ldpe-based blends and films stabilized with nonreleasing polymeric antioxidants for safer food packaging. J. Appl. Polym. Sci. 124, 3912-3920, https://doi.org/10.1002/app.35516 (2012).

25. Stagnaro, P. et al. Novel ethylene/norbornene copolymers as nonreleasing antioxidants for food-contact polyolefinic materials. J. Polym. Sci. B 51, 1007-1016, https://doi.org/10.1002/polb.23304 (2013).

26. Viglianisi, C. et al. Ethylene/hindered phenol substituted norbornene copolymers: Synthesis and nmr structural determination. J. Polym. Sci. A 50, 4647-4655, https://doi.org/10.1002/pola.26270 (2012).

27. Losio, S. et al. Fully consistent terpolymeric non-releasing antioxidant additives for long lasting polyolefin packaging materials. Polym. Degrad. Stab. 144, 167-175, https://doi.org/10.1016/j.polymdegradstab.2017.08.011 (2017).

28. Lethu, S., Matsuoka, S. \& Murata, M. Highly efficient preparation of selectively isotope cluster-labeled long chain fatty acids via two consecutive csp3-csp3 cross-coupling reactions. Org. Lett. 16, 844-847, https://doi.org/10.1021/ol4036159 (2014).

29. Starck, J.-P., Nakatani, Y. \& Ourisson, G. Synthesis of two new phospholipidic fluorescent probes for membrane studies. Tetrahedron 51, 2629-2638, https://doi.org/10.1016/0040-4020(95)00011-V (1995).

30. Shabany, H., Pajewski, R., Abel, E., Mukhopadhyay, A. \& Gokel, G. W. The effect of twin-tailed sidearms on sodium cation transport in synthetic hydraphile cation channels. J. Heterocycl. Chem. 38, 1393-1400, https://doi.org/10.1002/jhet.5570380623 (2001).

31. Kitano, Y. et al. Design and synthesis of anti-barnacle active fluorescence-labeled probe compounds and direct observation of the target region in barnacle cypris larvae for dimethyl-isocyanoalkyl compounds. Tetrahedron 61, 9969-9973, https://doi.org/10.1016/j. tet.2005.08.024 (2005).

32. Chinna Babu, P., Sundaraganesan, N., Dereli, O. \& Turkkan, E. FT-IR, FT-Raman spectra, density functional computations of the vibrational spectra and molecular geometry of butylated hydroxy toluene. Spectrochim. Acta A 79, 562-569, https://doi. org/10.1016/j.saa.2011.03.034 (2011).

33. Tanini, D. et al. Resveratrol-based benzoselenophenes with an enhanced antioxidant and chain breaking capacity. Org. Biomol. Chem. 13, 5757-5764, https://doi.org/10.1039/C5OB00193E (2015).

34. Burton, G. W. et al. Autoxidation of biological molecules. 4. Maximizing the antioxidant activity of phenols. J. Am. Chem. Soc. 107, 7053-7065, https://doi.org/10.1021/ja00310a049 (1985).

35. Jha, M. \& Pratt, D. A. Kinetic solvent effects on peroxyl radical reactions. Chem. Commun. 10, 1252-1254, https://doi.org/10.1039/ B800369F (2008).

36. Saito, S., Gao, H. \& Kawabata, J. Dpph (=2,2-diphenyl-1-picrylhydrazyl=2,2-diphenyl-1-(2,4,6-trinitrophenyl)hydrazyl) radicalscavenging reaction of protocatechuic acid esters $(=3,4$-dihydroxybenzoates $)$ in alcohols: Formation of bis-alcohol adduct. Helvetica Chimica Acta 89, 821-831, https://doi.org/10.1002/hlca.200690074 (2006).

\section{Acknowledgements}

We thank MIUR-Italy ("Progetto Dipartimenti di Eccellenza 2018-2022" allocated to Department of Chemistry "Ugo Schiff").

\section{Author contributions}

C.V. conceived the experiments and wrote the manuscript; A.S. and L.T. carried out the synthetic work, supervised by C.V. and S.M. conceived the study; A.B. conducted the autoxidation experiments supervised by R.A., S.M., R.A. and C.V. analysed the results. All authors reviewed the manuscript.

\section{Competing interests}

The authors declare no competing interests.

\section{Additional information}

Supplementary information is available for this paper at https://doi.org/10.1038/s41598-019-53531-5.

Correspondence and requests for materials should be addressed to C.V.

Reprints and permissions information is available at www.nature.com/reprints.

Publisher's note Springer Nature remains neutral with regard to jurisdictional claims in published maps and institutional affiliations.

Open Access This article is licensed under a Creative Commons Attribution 4.0 International License, which permits use, sharing, adaptation, distribution and reproduction in any medium or format, as long as you give appropriate credit to the original author(s) and the source, provide a link to the Creative Commons license, and indicate if changes were made. The images or other third party material in this article are included in the article's Creative Commons license, unless indicated otherwise in a credit line to the material. If material is not included in the article's Creative Commons license and your intended use is not permitted by statutory regulation or exceeds the permitted use, you will need to obtain permission directly from the copyright holder. To view a copy of this license, visit http://creativecommons.org/licenses/by/4.0/.

(C) The Author(s) 2019 